\title{
NOVEL NANO-CATALYSTS FOR WASTEWATER TREATMENT
}

\author{
H. HILDEBRAND* \\ K. MACKENZIE \\ F-D. KOPINKE
}

\author{
Helmholtz Centre for Environmental Research - UFZ \\ Department of Environmental Technology \\ Permoserstrasse 15, D-04318 Leipzig, Germany
}

Received: 06/11/07

Accepted: 14/12/07 *to whom all correspondence should be addressed: e-mail: heike.hildebrand@ufz.de

\section{ABSTRACT}

The present paper aims at a treatment technique designed for special industrial wastewaters contaminated with only traces of halogenated organic compounds (HOCs) - concentrations which are nevertheless large enough to make a discharge into municipal sewage works impossible. Our research follows the idea to detoxify the water by a selective destruction of the HOCs by hydrodehalogenation $(\mathrm{HDH})$ reactions on palladium-containing nano-catalysts. Detoxification means that persistent HOCs are converted into organic compounds which can easily be removed by biodegradation in a wastewater treatment plant.

A novel promising trend in environmental research is the application of nano-reagents (such as zero-valent iron) and nano-catalysts. As known from nano-sized metal particles, nanocatalysts have the advantage of very high reaction rates due to high specific surface areas and low mass-transfer restrictions. For special applications in wastewater treatment we were able to generate extremely active palladium catalysts on the basis of ferromagnetic carrier colloids. The magnetic nano-sized carriers (such as zero-valent iron or magnetite) were spiked with traces of $\mathrm{Pd}(0.1 \mathrm{wt} . \mathrm{\%})$. These nano-catalysts have been successfully tested in different reactor systems at the laboratory scale. Using Pd on nano-scale supports leads to enormous activity of the catalyst which is several orders of magnitude higher than reached in conventional fixed-bed reactors. The ferromagnetism of the carriers enables a separation of the catalysts from the treated water by means of magneto-separation. This gives the chance to reuse the catalyst several times.

The preferred reductant for the HDH reaction is molecular hydrogen. For highly contaminated waters, alternative hydrogen donors such as formic acid have been successfully tested.

KEYWORDS: nano-particles, catalysis, palladium, hydrodehalogenation reaction, wastewater treatment

\section{INTRODUCTION}

Halogenated organic compounds (HOCs) are among the most widely distributed water pollutants in industrialised countries. These organic molecules play an important role as solvents and additives in different industries such as the pharmaceutical production or in the IT branch. HOCs are mostly hazardous and toxic compounds which have very often a high persistence and may cause serious health problems such as cancer or mutagenic damage. Therefore, a complete destruction of these compounds is aspired or even mandatory. Ordinary wastewater treatment works cannot handle the problem. Thus, high priced and energy-intensive methods still have to be employed to solve this problem.

Common practice to dispose of industrial wastewaters contaminated with threshold load of organic solvents and only traces of HOCs is incineration. However, organic compounds such as alcohols could be removed by bacterial treatment in a wastewater treatment plant. The critical component leading to cost-intensive disposal is frequently the HOC. Current detoxification techniques such as adsorption on activated carbon or oxidation of the 
wastewater components do not lead to an environmentally friendly and economically priced solution. For example huge amounts of activated carbon would be necessary in order to remove $\mathrm{HOC}$ traces from water loaded with other sorption-active components. In the case of oxidation, excess amounts of oxidant are required because all reduced water components would be oxidized. The risk derives when insufficient amounts of oxidant are applied, that even more toxic components can occur if the oxidation is not complete. The last and often practised consequence is an excess-priced incineration. However, the incineration of aqueous waste is a waste of energy! Therefore, for a medium-sized enterprise a decentralized selective dehalogenation treatment of wastewater can give a significant economic advantage.

Our research follows the idea to detoxify the water by a selective destruction of the HOCs using the method of $\mathrm{HDH}$ on palladium-containing nano-catalysts. Detoxification means that persistent HOCs are converted into organic compounds which can easily be removed by biodegradation in a wastewater treatment plant. Reductive hydrodehalogenation reactions are very efficient and selective. That means, only the toxic and harmful halogenated compounds are affected by the catalytic reaction following the presented reaction type (Equation 1).

$$
\mathrm{RX}+\mathrm{H}_{2} \stackrel{\mathrm{Pd} \text {-catalyst }}{\longrightarrow} \mathrm{RH}+\mathrm{HX}
$$

For this reaction $\mathrm{H}_{2}$ or a hydrogen source as reducing agents are required. The products are predominantly non-toxic organic molecules and small amounts of HX. There are, however, some exceptions such as benzene formed by dechlorination of chlorobenzene. Palladium containing catalysts in the form of catalyst pellets are commonly used in fixed bed reactors in technical processes such as hydrogenation. For environmental applications such as ex-situ groundwater treatment, Pd catalysts have been tested already (Lowry and Reinhard, 2000; McNab et al., 2000). Kopinke et al. (2003) defined the specific catalytic activity $A_{P d}$ as measure of the Pd efficiency. The HDH reaction follows in many cases a $1^{\text {st }}$ order kinetics during the entire course of the reaction which makes it possible to characterise the specific catalyst activity by only one parameter: $A_{P d}\left[\mathrm{~g}^{-1} \mathrm{~min}^{-1}\right]$ according to Eq. 2 with $\mathrm{V}_{\text {water }}$ as the volume of the aqueous suspension, $m_{P d}$ the mass of $P d$ in the applied catalyst, $\tau_{1 / 2}$ the half-life of the $\mathrm{HOC}, \mathrm{t}_{1}$ and $\mathrm{t}_{2}$ are two arbitrarily chosen sampling times, $\mathrm{c}_{\mathrm{t} 1}$ and $\mathrm{c}_{\mathrm{t} 2}$ the corresponding HOC concentrations.

$$
\left.A_{P d}=\frac{V_{\text {water }}}{m_{P d} \cdot \tau_{1 / 2}}=\frac{\ln \left(c_{t 1} / c_{t 2}\right)}{\ln 2 \cdot c_{P d} \cdot\left(t_{1}-t_{2}\right)} \quad \text { (in }\left[1 \cdot g_{P d}{ }^{-1} \cdot \min ^{-1}\right]\right)
$$

This specific catalytic activity $A_{P d}$ allows comparing the capability of different palladium catalysts. Typical activities in fixed bed reactors using catalyst pellets are around $0.1-1 \mathrm{~L} \cdot \mathrm{g}_{\mathrm{Pd}}{ }^{-1} \cdot \mathrm{min}^{-1}(\mathrm{Lowry}$ and Reinhard, 2000; McNab et al., 2000). An activity of $100 \mathrm{I} \cdot \mathrm{g}_{\mathrm{Pd}}{ }^{-1} \cdot \mathrm{min}^{-1}$ describes a $98.5 \%$ detoxification of $1 \mathrm{~m}^{3}$ of water employing $1 \mathrm{~g}$ of $P d$ within the time of 60 minutes. In fixed bed reactors, the whole catalytic potential of the palladium cannot be fully utilized due to masstransport limitations. It is already known that the smaller the catalysts size, the higher the catalytic activity. This leads to the approach to utilize smaller catalyst particles such as fine grained powders or even nano-particles. A novel promising trend in environmental research is the application of nano-reagents (such as zero-valent iron (Liu et al., 2005)) and nanocatalysts. As known from nano-sized metal particles, nano-catalysts have the potential of very high reaction rates due to low mass-transfer limitations (Yuan and Keane, 2003).

For special applications in wastewater treatment we were able to generate extremely active palladium catalysts on the basis of ferromagnetic carrier colloids. The magnetic nano-sized carriers (such as zero-valent iron or magnetite) were spiked with traces of Pd (0.1 wt.-\%). The magnetic properties of the carriers ensure a separation of the catalyst from the treated water by means of magneto-separation (Franzreb, 2003). This gives the chance to reuse the catalyst several times. The magneto-separation technology bases on the application of strong electro- or permanent magnets. The efficiency of separation can even be enhanced by placing thin steel wires in the magnetic field (Figure 1). This technology ensures a high rate of the nano-catalysts recovery. In any case, nano-particles (especially containing Pd as a noble 
and heavy metal) should not leave the treatment system. We regard magnetite particles as attractive carriers when adding hydrogen or other hydrogen sources because it is sufficiently resistant against differing milieu parameters. Hydrogen has a water solubility of $\mathrm{S}_{\mathrm{H} 2}{ }^{15^{\circ} \mathrm{C}}=0.84 \mathrm{mM}$ at $\mathrm{p}_{\mathrm{H} 2}=100 \mathrm{kPa}$. This may be not enough for treatment of highly contaminated wastewaters. For example, from the stoichiometry of the hydrodechlorination reaction it follows that only up to $28.6 \mathrm{mg} \mathrm{l}^{-1}$ of trichloroethene (TCE) can be reduced with dissolved hydrogen $\left(\mathrm{C}_{2} \mathrm{HCl}_{3}+4 \mathrm{H}_{2} \rightarrow \mathrm{C}_{2} \mathrm{H}_{6}+3 \mathrm{HCl}\right)$. In practice, however, much higher $\mathrm{HOC}$ concentrations may occur. Formic acid as alternative $\mathrm{H}$-source was found to be as reactive as $\mathrm{H}_{2}$ under acidic and neutral conditions, but less reactive under alkaline conditions (Kopinke et al., 2004). In the framework of our studies in the field of wastewater treatment using nanosized catalysts for clean-up of HOC-contaminated wastewater, formic acid has already been tested and also found to be suitable as $\mathrm{H}$-donor. In addition, anaerobic iron corrosion can serve as hydrogen source. The iron corrosion may be the rate-limiting step in the reaction sequence when choosing nano-iron as catalyst carrier without an additional hydrogen source. In addition, the corrosion rate usually decreases over time. Nevertheless, iron is an environmentally friendly reagent with a relatively long lifetime, depending on the water chemistry ( $\mathrm{pH}$ and $\mathrm{E}_{\mathrm{H}}$ values, salinity) in the order of magnitude of $10^{2} \ldots 10^{3}$ days. The hydrogen-generating reaction in this system is the corrosion of iron according to $\mathrm{Fe}^{0}+2 \mathrm{H}_{2} \mathrm{O}$ $\rightarrow \mathrm{Fe}^{2+}+\mathrm{H}_{2}+2 \mathrm{OH}^{-}$. This may be an advantage for long-term reactions, where continuous hydrogen supply is desirable. It is not, however, an appropriate solution for fast reactions in relatively short time intervals. A big disadvantage would be loosing the palladium if the zerovalent iron carrier dissolves due to corrosion.

A desirable technological goal is an inexpensive reactor configuration where the catalytic system should be easy to handle. We regard agitated batch reactors as an attractive solution for steadily or discontinuously occurring small volumes of contaminated water. The water to be treated is mixed with the nano-catalyst and an $\mathrm{H}$-donor. During reaction the mixture is stirred continuously. After the complete dehalogenation, the catalyst is extracted from the detoxified water leaving the reactor by means of magneto-separation. The catalyst may then be reused in the next reaction cycle or collected for regeneration.

The catalytic material was tested in various technological options incl. batch and continuous flow reactors depending on kind and amount of wastewater. The catalytic activity of the described particles for probe HOCs such as chlorobenzene or TCE is extremely high (up to $\left.8000 \mathrm{~L} \cdot \mathrm{gPd}_{\mathrm{Pd}}{ }^{-1} \cdot \mathrm{min}^{-1}\right)$. This is several orders of magnitude higher than reached in conventional fixed bed reactors of granular catalysts for groundwater treatment. Structure-reactivity considerations allow the prediction of reactivities of various halogenated organic compounds in water clean-up processes. A correlation of $\mathrm{C}-\mathrm{X}$ bond strength with the $\mathrm{HDH}$ rate could be verified (Mackenzie et al., 2006). In contrast to straightforward structure-reactivity correlations found for chloroalkanes, $\mathrm{HDH}$ rates of chloroethenes and halobenzenes do not follow the order of the $\mathrm{C}-\mathrm{X}$ bond strength. The extremely high catalyst reactivity is of particular interest for the destruction of less reactive pollutants bearing C-F bonds.

For pollutant mixtures, HDH rates can be influenced by competition for Pd surface sites. Current studies also evaluate matrix effects (such as $\mathrm{pH}$, salinity, metal ions etc.) which could affect the catalysts activity. These studies give the chance to predict the suitability of the Pdmagnetite nano-catalyst for treatment of different wastewater types.

Due to the fact that catalysts in the nano-scale are also attractive for environmentally relevant in-situ applications (such as treatment of contaminated groundwater), it is necessary to characterize and evaluate their potential and at the same time possible risks they cause. The particle size determines not only the catalytic activity; it may as well be responsible for the ability of tiny particles to pass through cell membranes which bears the threat of their possible chemical reactions with cell constituents. Therefore, investigations concerning size-dependent cell toxicity of various kinds of nano-catalysts are necessary. In an interdisciplinary approach the chemical potential of such reactive systems has to be opened up with the simultaneous ecotoxicological weighing-up of possible risks. The evaluation of risks of such nano-sized catalysts for living cells plays an important role within the presented studies in order to demonstrate that the potential benefits outweigh the potential risks. 


\section{EXPERIMENTAL}

All reagents and HOCs were purchased in the highest grade available from Merck (Germany) or Sigma-Aldrich (Germany) and used as received.

$\mathrm{Pd} / \mathrm{Fe}_{3} \mathrm{O}_{4}$. The magnetite particles (Aldrich, $20 \ldots 30 \mathrm{~nm}$ ) were spiked in aqueous solution with $\mathrm{Pd}$ in the form of $\mathrm{Pd}(\mathrm{ac})_{2}$. This mixture was vigorously shaken for 1 hour. After decolourization of the orange solution (visible after magneto-separation), subsequent $\mathrm{H}_{2}$ treatment ensured complete reduction to $\mathrm{Pd}^{0}$. The catalyst was dried in vacuum and the $\mathrm{Pd}$ content was determined by X-ray fluorescence measurement. The catalysts used contained $0.1 \mathrm{wt}-\% \mathrm{Pd}$.

Dehalogenation studies. The dehalogenation activities of the nano-catalyst were studied in batch and column experiments using various probe HOCs such as chlorobenzene, chloroform and trichloroethylene. For tests with low HOC concentrations (1-20 ppm), clear screw-cap bottles $(250 \mathrm{ml})$ equipped with Mininert ${ }^{\circledR}$ valves were used. The $200 \mathrm{ml}$ reaction solution was extensively purged with $\mathrm{H}_{2}$ after adding the catalyst (5-50 mg catalyst, corresponding to a $\mathrm{Pd}$ input of $\left.25-250 \mu \mathrm{g} \mathrm{I}^{-1}\right)$. The batch bottle was treated in the ultrasonic bath for about $10 \mathrm{~min}$. The HOCs were added as a methanolic solution. The catalyst concentration was adjusted to the reaction rates in such a way that a sufficient number of samples could be analysed over the course of reaction. The headspace over the suspension $(50 \mathrm{~mL})$ was pure $\mathrm{H}_{2}$, forming a sufficient reservoir for the reductant. The reaction was started by adding the HOC stock solution, carefully excluding air. The bottle was then continuously shaken (210 rpm) throughout the experiment. The reaction kinetics was monitored by means of headspace analyses of educts and products using a GC-MS device (QP 2010, Shimadzu Corp., equipped with a DB1 capillary column). The experimental set-up chosen is based upon the following conditions: (i) the proportion of HOCs present in the headspace is small compared to that in the water phase $\left(K_{\text {Henry }} V_{\text {headspace }} V_{\text {water }}\right.$ 《 1$)$, (ii) the $\mathrm{H}_{2}$ demand for complete HDH is small compared to the total hydrogen amount present in the reactor bottle (dissolved and headspace) and (iii) the mass transfer between aqueous and gas phase is fast compared to the overall reaction rates.

The tests with formic acid as $\mathrm{H}$-donor were carried out comparable to the described batch experiments. Formic acid was given to the $200 \mathrm{ml}$ reaction solution which was previously purged with nitrogen to avoid any air in the batch bottle. The $\mathrm{pH}$ was adjusted by adding $\mathrm{NaOH}$ with a micro litre syringe. The probing was carried out by headspace sampling with a $25 \mu$ l gastight syringe.

The column experiments were carried out using a $3 \mathrm{~m}$ long glass tube with an inner diameter of $3 \mathrm{~mm}$ and an outer diameter of $6 \mathrm{~mm}$. The glass tube was arranged as a coil for better handling. The coil was fed with HOC-containing water $\left(\mathrm{C}_{0, \mathrm{HOC}} \approx 20 \mathrm{ppm}\right)$ which was pumped with a flow rate of $9.7 \mathrm{ml} \mathrm{min}^{-1}$ (piston pump, ISMATEC MCP). In a distance of $10 \mathrm{~cm}$ from the coil inlet, a sampling port with a Luer Lock adapter was installed for liquid sampling by means of glass syringes. In addition, a second inlet at this point fed by a smaller piston pump was used for adding the catalyst suspension. After $3 \mathrm{~m}$ reactor length, a second sampling port was installed for gaining liquid samples of the reaction suspension. The magneto-separation of the catalyst particles was carried out in a small glass vessel at the reactor outlet, which was filled with stainless steel wool. The vessel was placed into a strong magnetic field generated by permanent magnets fixed at the outside of the vessel. The liquid samples were filled in small vials and the catalyst was poisoned by adding sodium sulphide solution in order to prevent further reaction. A $25 \mu \mathrm{l}$ sample was taken in the headspace of the aqueous suspension and analysed using GC/MS.

\section{RESULTS AND DISCUSSION}

Magnetite nano-particles were impregnated with palladium clusters by wet treatment followed by a reduction step. With this catalytic system, various tests have been carried out. First, the $\mathrm{Pd}$ content was determined. The result showed that all the introduced Pd precipitated on the magnetite surface $\left(\mathrm{C}_{\mathrm{Pd}}=0.1 \mathrm{wt}-\%\right)$. There was no loss of palladium observed.

The $\mathrm{Pd} /$ magnetite catalyst was then tested in batch experiments under various conditions. The results show, that very high catalytic activities (up to $8000 \mathrm{I} \cdot \mathrm{gpd}^{-1} \cdot \mathrm{min}^{-1}$ ) could be found for different test substances such as chlorobenzene (MCB) or TCE. Pd activities of $0.1 \mathrm{l} \cdot \mathrm{g}_{\mathrm{Pd}}{ }^{-1} \cdot \mathrm{min}^{-1}$ 
were found in field tests for groundwater treatment using granular Pd catalysts such as $\mathrm{Pd}$ on $\mathrm{y}$-alumina (McNab et al., 2000). This shows that the inherent $\mathrm{Pd}$ activity is much higher than utilizable in the conventional environmental applications. Indeed, the determined activities with the described nano-catalyst are several orders of magnitude higher than can be achieved in fixed bed arrangements of granular catalysts for groundwater treatment. The minimized particle size allows minimized mass transport limitations. The short reaction times permit an efficient decontamination of the wastewaters in focus.

In the case of wastewater treatment we are not faced with the same problems as known from groundwater treatment. We may be able to predict precisely, how the catalyst will perform under certain water conditions. Therefore, studies are on the way to test the influence of various matrix parameters on the catalyst performance. The magnetite carrier particles proved their applicability under a wide range of milieu conditions. Tests with catalyst suspensions showed that after 4 days exposure at a pH value of 7 only $1.5 \%$ of the employed iron (as iron oxide) was dissolved. That means, only $1.5 \%$ of the carrier material was thereby lost. If the $\mathrm{pH}$ value is higher, even less dissolved iron could be found (e.g. at $\mathrm{pH}$ $=8.5$ only $0.04 \%$ of the total iron). Lower $\mathrm{pH}$ values lead to a higher loss of carrier material. At $\mathrm{pH}=5$ about $6.5 \%$ of the total iron were found in solution after 4 days. However, wastewater to be discharged into a wastewater treatment plant has to be neutralized in any case. Therefore, an acidic reaction milieu should be avoided during reaction. The dissolution of $\mathrm{Pd}$ corresponds with the measured dissolution of magnetite. In experiments with $\mathrm{c}_{\text {cat }}=100$ $\mathrm{mg} \mathrm{l}^{-1}$ at $\mathrm{pH}=7$ only about $1 \%$ of the total $\mathrm{Pd}$ was found dissolved, whereas about $50 \%$ of the employed palladium was released after 4 days in a suspension at $\mathrm{pH}=3$. This seems to be a lot, but it is easy to explain if we consider, that the total amount of Pd is attached to the magnetite surface. If the magnetite itself is dissolved, palladium will get detached from the carrier material. If we consider a loss of $1 \%$ of the total Pd mass, this means that the concentration of leached $\mathrm{Pd}$ is approx. $2 \mathrm{\mu g} \mathrm{I}^{-1}$ (when the initial catalyst concentration was $100 \mathrm{mg} \mathrm{l}^{-1}$ ). Leached palladium can be effectively removed by an iron bed by means of reduction and precipitation on the iron surface.

In contrast to magnetite as carrier colloid, iron nano-particles are able to provide hydrogen. However, the more acidic the reaction solution, the lower is the life-time of the carrier material. As mentioned above, we regard magnetite particles as more attractive carriers when adding hydrogen or other hydrogen sources. In batch experiments, tests with formic acid as $\mathrm{H}$-donor were carried out. From previous studies it is already known, that formic acid can easily serve as hydrogen donor under acidic conditions.

At $\mathrm{pH}=3$, a specific Pd-activity of $200 \mathrm{I} \cdot \mathrm{gPd}^{-1} \cdot \mathrm{min}^{-1}$ was found for the test substance MCB. In this case, most likely the decomposition of the formic acid $\left(\mathrm{HCOOH} \rightarrow \mathrm{H}_{2}+\mathrm{CO}_{2}\right)$ is the rate limiting step of the reaction. In some experiments with formic acid, a shift from a first order kinetics to zero order kinetics was observed. Formic acid was found to serve as efficient $\mathrm{H}$ source in a relatively wide $\mathrm{pH}$ range. Nano-sized $\mathrm{Pd} /$ magnetite catalysts can even be stored as a suspension in formate solution $(\mathrm{pH}>8)$ without loss of activity. This mixture can be seen as part of a wastewater-treatment toolkit. Studies involving other $\mathrm{H}$-donors such as hydrazine are in progress. For larger volumes of contaminated wastewater, flow-through reactors would be the first choice. In the laboratory scale smaller-sized continuous flow reactors have been successfully tested. Figure 2 shows the result of the study using MCB as probe molecule. The abscissa gives the duration of the experiment. After 10 minutes a stationary conversion degree had been established for the experimental conditions chosen. MCB and benzene concentrations found at the reactor outlet reached a constant value over the duration of the experiment. The catalysts activity was stable at a high level (approx. $3000 \mathrm{~L} \cdot \mathrm{g}_{\mathrm{Pd}}{ }^{-1} \cdot \mathrm{min}^{-1}$ ). The transport of the nano-catalysts through the reactor was especially in the beginning of the experiment very homogeneous over the whole length of the coil. The $\mathrm{Pd}$ activity was calculated according to equation (3) for flow-through reactors with $\tau_{\text {reactor }}$ as the hydraulic residence time of the eluent in the reactor. 


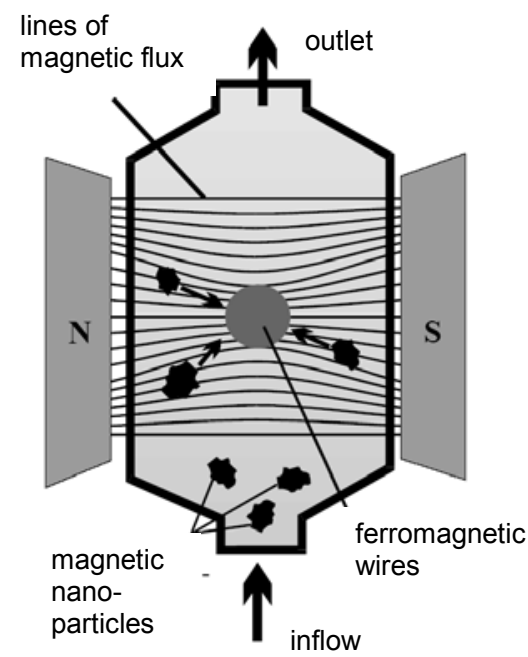

Figure 1. Magneto-separation technology (Franzreb, 2003)

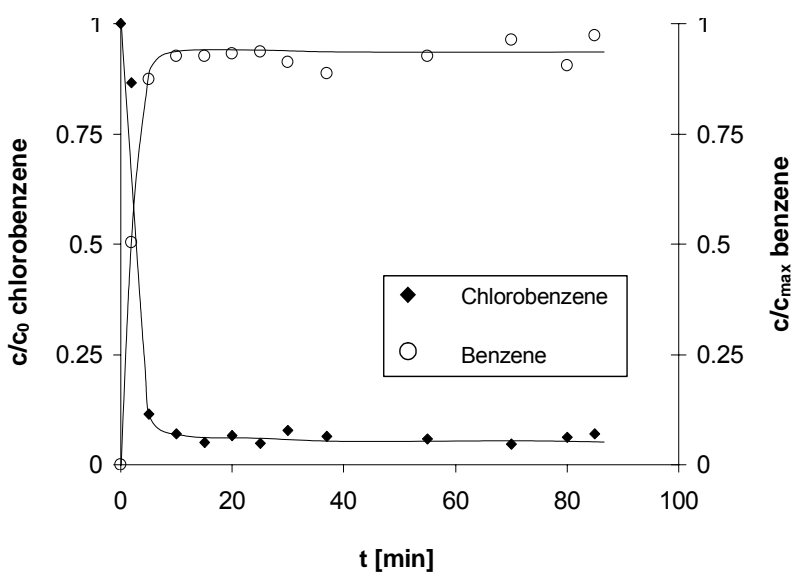

Figure 2. Chlorobenzene dechlorination in a continuous flow-through reactor with continuous feed of $\mathrm{Pd} / \mathrm{Fe}_{3} \mathrm{O}_{4}$ nano-catalysts $\left(\mathrm{c}_{0, \mathrm{MCB}}=20 \mathrm{mg} \cdot \mathrm{l}^{-1}\right.$, $\left.\mathrm{C}_{\mathrm{Pd}}=0.25 \mathrm{mg} \cdot \mathrm{I}^{-1}, \mathrm{~T}_{\text {reactor }}=2 \mathrm{~min}\right)$

$$
A_{P d}=\frac{\ln \left(\frac{c_{0}}{c}\right)}{c_{P d} \cdot T_{P d} \cdot \ln 2}
$$

The extraction of the magnetite particles from the reaction suspension by means of magnetoseparation was carried out as described above with a high efficiency. In a test with the continuous flow-through reactor, $97.6 \%$ of the introduced amount of the $\mathrm{Pd} /$ magnetite nanocatalyst was recovered in the magneto-separation vessel. The remaining $2.4 \%$ divide into the dissolved fraction and a remaining thin film of particles precipitated on the reactor walls. If we use the same catalyst material for several reaction cycles we can observe, that the tendency for dissolution of the catalyst decreases. This supports the hypothesis, that initially all easy to dissolve components of the catalyst leach from the surface and the remaining material is very resistant against further dissolution.

The results shown prove that a continuous flow-through reactor is a suitable reactor type for treatment of continuously occurring HOC-contaminated wastewater. The extremely high catalyst activities, the stability of the $\mathrm{Pd} /$ magnetite system in a near-neutral reaction medium and the good recovery rates of the catalyst by magneto-separation are very promising preconditions for a successful application of the novel catalyst system for wastewater treatment process.

The chemical potential of such reactive systems is enormous, but it can only be exploited responsibly on the basis of a thorough ecotoxicological analysis of possible risks. The evaluation of the risks of such nano-catalysts for living cells plays an important role within the presented studies. Of course we hope that the benefits will be found to outweigh the potential risks.

\section{CONCLUSIONS}

Extremely active catalysts for cyclic batch or continuous flow-through reactor applications can be produced on the basis of ferromagnetic nano-sized carrier colloids (magnetite, $\mathrm{Fe}_{3} \mathrm{O}_{4}$ ) containing only traces of $\mathrm{Pd}(0.1 \mathrm{wt}-\%)$. Nano-sized $\mathrm{Pd}$ catalysts have been successfully tested for selective hydrodehalogenation of wastewater pollutants at the laboratory scale. Dehalogenation using $\mathrm{Pd}$ on nano-scale supports shows the true inherent activity of $\mathrm{Pd}$ clusters which is several orders of magnitude higher than reached in fixed-bed arrangements due to minimized mass-transfer limitations. Magnetite particles are suitable catalyst carriers because of their rather high resistance against milieu parameters. Their magnetism allows the 
extraction of the nano-particles from the treated water by means of magneto-separation which makes a reuse of the catalyst possible. Alternative $\mathrm{H}$-donors such as formic acid was successfully tested. Beside the study of the opportunities and the high potentials of such catalyst systems, the evaluation of their potential environmental risks is in progress.

\section{REFERENCES}

Franzreb M. (2003) Magnettechnologie in der Verfahrenstechnik wässriger Medien, Wissenschaftliche Berichte FZKA 6916, Karlsruhe.

Kopinke F-D., Mackenzie K., Koehler R. and Georgi A. (2004) Alternative sources of hydrogen for hydrodechlorination of chlorinated organic compounds in water on Pd catalysts, Appl. Catal. A: General, 271, 119-128.

Kopinke F-D., Mackenzie K. and Köhler R. (2003) Catalytic hydrodechlorination of groundwater contaminants in water and in gas phase using $\mathrm{Pd} / \gamma-\mathrm{Al}_{2} \mathrm{O}_{3}$, Appl. Cat. B: Environmental, 44, 15-24.

Liu Y, Majetich S., Tilton R.D., Sholl D.S. and Lowry G.V. (2005) TCE dechlorination rates, pathways, and efficiency of nanoscale iron particles with different properties, Environ. Sci. Technol., 39, 1338-1345.

Lowry G.V. and Reinhard M. (2000) Pd-Catalyzed TCE Dechlorination in Ground-water: Solute Effects, Biological Control, and Oxidative Catalyst Regeneration, Environ. Sci. Technol., 34, 3217-3223.

Mackenzie K., Frenzel H. and Kopinke F.-D. (2006) Hydrodehalogenation of Halogenated Hydrocarbons in Water with Pd Catalysts: Reaction Rates and Surface Competition, Appl. Catal. B: Environmental, 63, 161-167.

McNab W.W., Ruiz R. and Reinhard M. (2000) In-situ destruction of chlorinated hydrocarbons in groundwater using catalytic reductive dehalogenation in a reactive well: Testing and operational experiences, Environ. Sci. Technol., 34, 149-153.

Mc-Nab W.W., Ruiz R. and Reinhard M. (2000) Palladium-Catalyzed Reductive Dehalogenation of Dissolved Chlorinated Aliphatics using Electrolytically Generated Hydrogen, Environ. Sci. Technol., 34, 149- 153.

Yuan G. and Keane M.A. (2003) Liquid phase catalytic hydrodechlorination of 2,4-dichlorophenol over carbon supported palladium: an evaluation of transport limitations, Chem. Eng. Sci., 58, 257-267. 